\title{
An essential role for mast cells as modulators of neutrophils influx in collagen-induced arthritis in the mouse
}

\author{
Tatiana Aparecida Pimentel ${ }^{1,5}$, André Luiz Franco Sampaio ${ }^{2,3,5}$, Fulvio D'Acquisto ${ }^{2}$, Mauro Perretti ${ }^{2}$ \\ and Sonia Maria Oliani ${ }^{1,4}$
}

Mast cells are involved in immune disorders so that many of the proinflammatory and tissue destructive mediators produced by these cells have been implicated in the pathogenesis of rheumatoid arthritis. This scenario prompted us to investigate the correlation between mast cell degranulation and neutrophil influx within the digits and knees joints of arthritic mice assessing what could be the functional role(s) of joint mast cells in the response to collagen immunization. DBA/1J mice were submitted to collagen-induced arthritis and disease was assessed on day 21, 32 and 42 post-immunization. Pharmacological treatment with the glucocorticoid prednisolone, commonly used in the clinic, and nedocromil, a mast cell stabilizer, was performed from day 21 to 30. Arthritis develop after immunization, gradually increased up to day 42 . Neutrophil infiltration peaked on day 32 and 21, in the digits and knees, respectively, showing an unequal pattern of recruitment between these tissues. This difference emerged for mast cells: they peaked in the digits on day 21, but a higher degree of degranulation could be measured in the knee joints. Uneven modulation of arthritis occurred after treatment of mice with prednisolone or nedocromil. Neutrophils migration to the tissue was reduced after both therapies, but only prednisolone augmented mast cell migration to the joints. Nedocromil exerted inhibitory properties both on mast cell proliferation and migration, more effectively on the digit joints. Thus, collagen induced an inflammatory process characterized by tissue mast cells activation and degranulation, suggesting a potential driving force in propagating inflammatory circuits yielding recruitment of neutrophils. However, the different degree of affected joint involvement suggests a time-related implication of digits and knees during collagen-induced arthritis development. These results provide evidence for local alterations whereby mast cells contribute to the initiation of inflammatory arthritis and may be targeted in intervention strategies.

Laboratory Investigation (2011) 91, 33-42; doi:10.1038/labinvest.2010.140; published online 16 August 2010

KEYWORDS: collagen-induced arthritis; digits; knees; mast cells; nedocromil; neutrophils; prednisolone

Rheumatoid arthritis is a chronic inflammatory disease involving complex immunologic mechanisms including inflammation, immunologic tolerance and autoimmunity, all contributing to the destruction of cartilage and bone. ${ }^{1,2}$ Active rheumatoid arthritis is characterized by a strong inflammatory reaction and hyperplasia of synovial tissue. Histologically there is presence of $\mathrm{T}$ lymphocytes, B lymphocytes, macrophages and mast cells in the synovial membrane and fluid compartment. ${ }^{3-5}$
Traditionally, mast cells and immunoglobulin E (IgE) have long been associated with the pathogenesis of immediate hypersensitivity reaction, the pathophysiologic hallmark of allergic rhinitis, allergic asthma, and anaphylaxis. ${ }^{6}$ IgE-dependent activation of mast cells leads to the secretion of preformed mediators (such as vasoactive amines and neutral proteases), proinflammatory lipid mediators, that are synthesized anew, and growth factors, cytokines and chemokines. ${ }^{7}$ However,

\footnotetext{
${ }^{1}$ From the Post-Graduation in Morphology, Federal University of São Paulo (UNIFESP), Paulista School of Medicine (EPM), Rua Botucatu, São Paulo, Brazil; ${ }^{2}$ The William Harvey Research Institute, Barts and The London Medical School, Queen Mary University of London, Charterhouse Square, London, UK; ${ }^{3}$ FarManguinhos - FIOCRUZ, Rua Sizenando Nabuco, Rio de Janeiro, Brazil and ${ }^{4}$ Department of Biology, Instituto de Biociências, Letras e Ciências Exatas, São Paulo State University (UNESP), Rua Cristóvão Colombo, São José do Rio Preto, São Paulo, Brazil

Correspondence: Professor SM Oliani, Department of Biology, IBILCE - UNESP, Rua Cristóvão Colombo 2265, São José do Rio Preto, São Paulo, 15054 - 000 , Brazil. E-mail: smoliani@ibilce.unesp.br

${ }^{5}$ These two authors contributed equally to this work.
}

Received 27 December 2009; revised 17 May 2010; accepted 14 June 2010 
mast cells can be activated to perform important effector and immunomodulatory functions by mechanisms that are independent of IgE; thus, the type of stimulus can determine the kinetics, amounts and/or spectrum of mediators that are released from this cell type. ${ }^{7-10}$ As an example, mast cells are involved in autoimmune disorders and many of the proinflammatory and tissue destructive mediators produced by these cells have been directly implicated in the pathogenesis of rheumatoid arthritis and other rheumatic diseases. ${ }^{5,11}$

Although mast cells have been implicated in arthritis, the exact mechanism(s) by which they cause damage has not been defined. One possibility would be that the proteases that are released upon degranulation, eg, chymases, contribute to disease. Recent findings showed a pathogenic role of mouse mast cell protease 4 (mMCP-4) in autoimmune arthritis. ${ }^{12}$ It therefore seems likely that activated mast cells are a driving force in propagating microenviromental inflammatory circuits, by recruiting other types of cells, perhaps the neutrophils, ${ }^{13}$ and inducing proteolytic and cytokine activities in the local environment. ${ }^{14}$

Congruently, mice lacking mast cell tryptase/heparin complexes have attenuated arthritic responses; mouse mast cell protease (mMCP-6) appears to be the dominant tryptase responsible for favoring neutrophil infiltration in the $\mathrm{K} / \mathrm{BxN}$ mouse serum-transfer arthritis model. ${ }^{15}$ The biologic consequences of the activation and degranulation of mast cells in the rheumatoid synovial tissue are complex and despite their ability to mediate inflammation was neglected for years, the mast cell and its products are now recognized as novel targets for therapy of rheumatoid arthritis. ${ }^{14}$

The anti-allergic nedocromil is a 'cromoglycate-like' drug (cromolyn) that impairs the release of inflammatory mediators from activated mast cells. ${ }^{16}$ Whereas nedocromil possesses anti-allergic properties, ${ }^{3,17}$ its potential impact on classical inflammatory and arthritic responses is less studied. Thus, we have used here a model of rheumatoid arthritis, the collageninduced arthritis (CIA) in the mouse, to monitor mast cell status in two distinct joints; we have then tested the effect of a mast cell stabilizer in comparison to a well-accepted antiarthritic therapy, the glucocorticoid prednisolone.

\section{MATERIALS AND METHODS Animals}

DBA/1J male mice weighing 18-22 g (Harlan, UK) each were used for all experiments. Animals were maintained on a standard chow pellet diet with tap water ad libitum and housed at a density of five animals per cage in a room with controlled lighting (lights on from 8:00 a.m. to 8:00 p.m.) in which the temperature was maintained at $21-23^{\circ} \mathrm{C}$. Animal work was performed according to UK Home Office regulations (Guidance on the Operation of Animals, Scientific Procedures Act 1986) and this study was approved by the Committee of Ethics in Research of the São Paulo School of Medicine, UNIFESP (CEP-process 0951/05).

\section{Collagen Induced Arthritis (CIA)}

Bovine type II collagen (CII) was dissolved at $4^{\circ} \mathrm{C}$ in $0.1 \mathrm{M}$ acetic acid to a concentration of $2 \mathrm{mg} / \mathrm{ml}$. Mice were immunized intradermally, at the base of the tail, with $100 \mu \mathrm{g}$ bovine CII emulsified in an equal volume of Freund's incomplete adjuvant (Sigma, UK) and Mycobacterium tuberculosis H37Ra (Gibco; $2 \mathrm{mg} / \mathrm{ml}$ ). Booster injection of CII dissolved in Freund's incomplete adjuvant was given 21 days after the first immunization. Nonimmunized mice received similar injections but without the antigen CII. DBA/1J mice were divided into 4 experimental groups, with 5 animals each. Mice were killed 21, 32 or 42 days after the first immunization.

\section{Drug Treatments}

Sodium nedocromil (generous gift of Sanofi-Aventis, London, UK; $2 \mathrm{mg} / \mathrm{kg}$ ) and prednisolone (21-Hemisuccinate salt, Sigma-Aldrich, Poole, UK; $4 \mu \mathrm{mol} / \mathrm{kg}$ ) were given orally or subcutaneously, respectively, over a 10 day period starting at day 22. Compounds were diluted with sterile saline immediately before use.

\section{Assessment of Clinical Score and Paw Volume}

A clinical score was allocated to each mouse every other day from day 7 to day 42 . The clinical severity of arthritis was quantified according to the swelling of four paws.

For scoring, each paw was evaluated for paw and digit swelling. For each hind paws a maximum score of 6 was given (12 max for both), giving a value of 1 for each toe ${ }^{5}$ and a value of 1 for the total assessment of the paw. For the forepaws, a maximum of 5 could be reached (max 10 for both), counting 1 for each toe (hence max possible of 4) and 1 for the paw (in the forepaw the pollex was not considered for scoring). With respect to the affected toes, there was no distinction if one or more than one joint in the same toe were affected, so the max scored is 1 . Redness was not considered itself for scoring but only as contributor to the score of a given toe when accompanied by mild swelling. When each single paw was graded a maximal score of 22 could be given to each mouse.

Paw volumes were assessed daily from day 7 to day 42 after immunization, using a hydropletysmometer (Ugo Basile, Milan, Italy). Paw volume was calculated in $\mu \mathrm{l}$ by subtracting the initial paw volume (basal) to the values measured at each time point (oedema). The knees were not evaluated macroscopically but only by histology.

\section{Fixation, Processing, and Embedding for Light Microscopy}

The knees and digits joints were dissected and fixed in $4 \%$ paraformaldehyde, $0.5 \%$ glutaraldehyde and $0.1 \mathrm{~mol} / \mathrm{l}$ sodium cacodylate buffer $(\mathrm{pH} 7.4)$ for $24 \mathrm{~h}$ at $4^{\circ} \mathrm{C}$. They were then washed in sodium cacodylate, dehydrated through graded percentages of methanol and embedded in LRWhite (London Resin Co., Reading, Berkshire, UK). Sections ( $1 \mu \mathrm{m}$ 

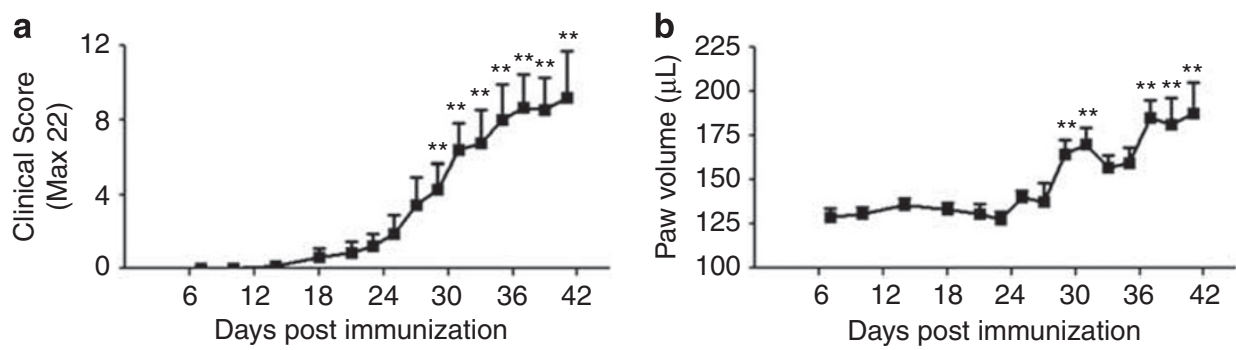

Figure 1 Development and progression of collagen-induced arthritis (CIA) in DBA/1J mice. Clinical score (a) and paw volume (b) were analyzed from day 7 after collagen immunization until day 42 . Clinical score demonstrated a progressive development of arthritis mainly after the booster, on day 21 . It was detected a significantly greater paw volume on day 32 with a peak on day 42 . Values are the mean and s.e.m. taking a $P$-value less than 0.05 as significant ( $n=5$ animals per group). ${ }^{* * P}<0.01$ vs day 21 (one way ANOVA followed by test for linear trend between means and Dunnett's post hoc test).

thick) were cut on an ultramicrotome (Leica RM2265, Leica, Germany), stained with $1 \%$ toluidine blue in $1 \%$ borax solution (TAAB Laboratories, Aldermaston, Berkshire, UK) and by Picrosirius and hematoxylin-eosin (H\&E-stain) methods. Sections of digits and knees joints were analysed on an Axioskop 2-Mot Plus Zeiss microscope (Carl Zeiss, Jena, Germany) for quantification of mast cells and neutrophils. The histological analysis was performed using a high power objective (x63) in the microscope ZEISS - AXIOSKOP 2, by counting cells in three areas with a minimum of approximately $100 \mu \mathrm{m}^{2}$, using three distinct serial sections $(50 \mu \mathrm{m}$ interval between sections) per animal, for five different animals. The presence of mast cells and neutrophils was determined in different areas of the synovial tissue and joint space. Degranulated mast cells were identified by the reduced presence of cytoplasmatic granules. Values are shown as mean \pm s.e.m, of cells number per $\mathrm{mm}^{2}$ ).

\section{Data Handing and Statistical Analysis}

Quantification of neutrophils and mast cells number in the digits and knees synovial tissue was performed with the image analysis system (AxioVision Software, Zeiss) (analyzing at least five distinct sections per mouse). The histological analysis was performed using a high power objective (x63) in the Axioskop 2-Mot Plus Zeiss microscope (Carl Zeiss, Jena, Germany). This also allowed morphological analysis of mast cell degranulation as determined by the presence of extravasated cytoplasmic granules in the tissue. Data are reported as mean \pm s.e.m. of $n=5$ mice per group. Experimental groups were analysed using one way ANOVA followed by Dunnett's or post hoc test for linear trend between means, as appropriate ( $>2$ groups, parametric data), or Student's $t$-test for two selected groups. $P$-Values lower than 0.05 were considered significant.

\section{RESULTS}

\section{Time-Course of CIA in DBA/1J Mice}

The development of inflammation was assessed by scoring the clinical disease activity and measuring changes in paw volumes. Arthritis developed in DBA/1J mice after intradermal injection of CII from $\sim$ day 20 , with a rapid clinical progression (Figure 1a) that we monitored up to day 42. With respect to the paw, during the initial phase a moderate increase in the paw volume was noted (Figure 1b): a significantly elevated level of inflammation was measured on day 32 , with a further exacerbation $(P<0.001)$, through some variations, up to day 42 (Figure $1 \mathrm{~b}$ ).

\section{Histopathological Analysis of the Digits and Knees Joints on CIA}

Histopathologic analysis of picrosirius and H\&E-stained tissue sections demonstrated accumulation of transmigrated neutrophils in the digits, which steadily increased from day 21 , reaching a peak at day 32 post-CII (Figure $2 \mathrm{a}-\mathrm{i}$ ). In the knee synovial tissue samples, neutrophil number was also modulated by the immune response to CII, but the peak was now reached by day 21 , followed by a substantial $(>50 \%)$ reduction progressively to day 32 and day 42 (Figure $2 j-r$ ). Moreover, there were statistical differences between digit and knee neutrophils number $(P<0.001$, on 21,32 and 42 days $)$, with a consistent lower presence of this cell type in the knee synovial tissue.

In addition to the profile of neutrophil recruitment to the synovial tissue, there were significant alterations in the infiltration of these cells within the joints. Analysis of serial joint tissue sections showed significantly augmented neutrophil number in the knees joint space of DBA/1J mice submitted to CIA, on day $21\left(2,00 \pm 0.32\right.$ cells $\left./ \mathrm{mm}^{2}\right)$, day 32 $\left(1,17 \pm 151.90\right.$ cells $\left./ \mathrm{mm}^{2}\right)$ and day $42(641.40 \pm 0.50$ cells/ $\mathrm{mm}^{2}$ ), in relation to non-arthritic animals, where this cell type was rarely detected $\left(5.1 \pm 1.90\right.$ cells $\left./ \mathrm{mm}^{2}\right)$.

Mast cells morphology was also analyzed both in digit and knee synovial tissue samples, using toluidine blue staining. Histology of the digits joints showed presence of intact mast cells, with their characteristic metachromatic granules (Figure $3 \mathrm{a}-\mathrm{e}$ ): in some cases these cells were localized close to blood vessels both in control mice and at day 21 of the CIA response (Figure 3a and $\mathrm{b}$ ). The number of degranulated mast cells was constant over the period under observation ranging between 31 and $35 \%$ for both day 21,32 and 42 (Figure 3a-e). In contrast to these results in the digits, knees joint sections displayed a lower total number of mast cells, 


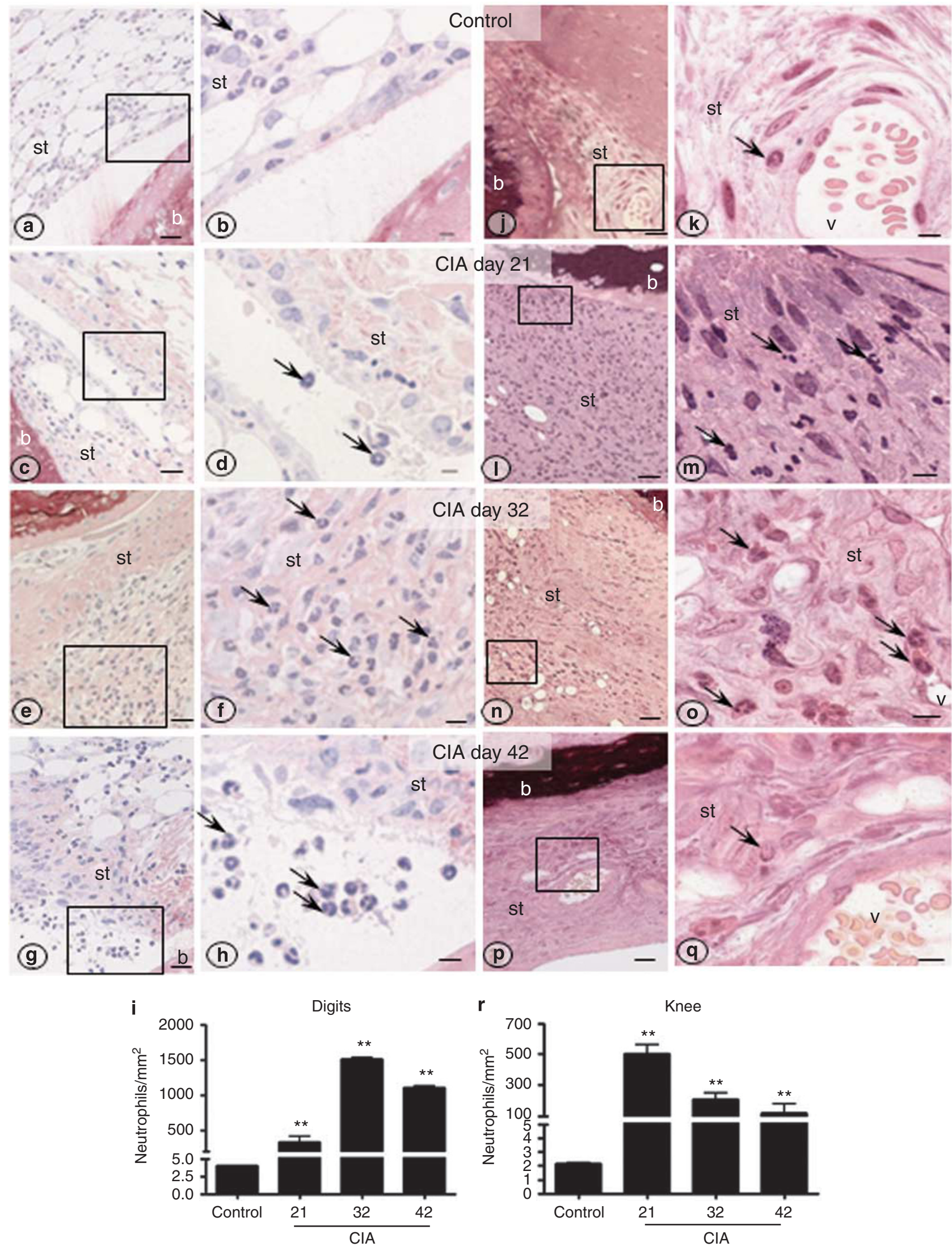


but the large majority of them were degranulated: this effect peaked at day 21 ( $>80 \%$ degranulation) and decreased over time up to $<30 \%$ degranulation on day 42 (Figure $3 \mathrm{f}-\mathrm{j}$ ). In addition, comparison of intact mast cells in the digits and knees revealed a significant increase in the first compartment $(P<0.05$ at both day 21, 32 and 42$)$; moreover, the extent of degranulated cells was also higher in the digits $(P<0.01$, day 32 and 42).

\section{Effects of Prednisolone and Nedocromil}

Treatment of mice with either prednisolone or nedocromil inhibited development of arthritis after CII administration, evident both for clinical score and paw volume measurements. Of interest, these compounds exerted different pattern of actions: the inhibition attained by prednisolone was high and constant over time, evident both for the clinical score and the paw volume (Table 1, data for day 27 and 32). In contrast, nedocromil produced a significant degree of inhibition on the clinical score, higher than on paw volume; in either case, the maximal effect was evident at day 27, with much more modest values at day 32 (Table 1).

These macroscopic analyses were complemented by histological determinations, performed on day 32. Treatment of mice with prednisolone markedly reduced cell recruitment both in digits (Table 2) and knees (Table 3). Images in Figure $4 \mathrm{a}-\mathrm{c}$ provide representative snapshots of these effects. Prednisolone inhibited neutrophil infiltration in the digit by $>80 \%$, with a much more modest effect in the knee $(\sim 25 \%$ inhibition; though statistically different, $P<0.001)$. Mast cell analysis revealed that prednisolone produced a marked mastocytosis, with an approximate 10-fold increase in tissue mast cell numbers both in digits and knee tissue samples (Figure 4d-f; Tables 2 and 3) $(P<0.001$, both for intact and degranulated mast cells). With respect to the extent of degranulation, in the digits $\sim 33 \%$ of mast cells were degranulated and a similar incidence was calculated after treatment with prednisolone (Table 2); in the knees, however, $\sim 66 \%$ of mast cell degranulation was calculated in untreated arthritic mice, whereas $\sim 30 \%$ degranulation could be calculated in the glucocorticoid group (Table 3 ).

Nedocromil exerted inhibitory properties on neutrophil recruitment both in digit and knee joints, with a much higher degree of efficacy in the latter tissue (Figure $4 \mathrm{c}-\mathrm{f})(P<0.001)$. In fact, whereas neutrophil reduction in the digits was $\sim 80 \%$ (Table 2), it reached $>95 \%$ in the knee joints (Table 3 ). It was important to validate the effect of nedocromil on mast cell integrity. Treatment with this compound did not provoke mastocytosis and actually seemed to reduce total mast cell numbers (40 vs 18 and 8 vs 2 mast cells per $\mathrm{mm}^{2}$ for digists and knees, in arthritic and nedocromil-treated mice, respectively). However, at this late time-point, the degree of degranulation was modestly affected (Tables 2 and 3 ). Consistent with these findings, statistical analysis clearly showed difference in the number of intact and degranulated mast cells between digits and knees $(P<0.001)$.

\section{DISCUSSION}

Experimental arthritis is widely used as a preclinical model predictive for drug efficacy in human settings. This is particularly true for the collagen-induced arthritis (CIA) model. ${ }^{18}$ Injection of bovine type II collagen would induce an immune response with consequent $\mathrm{B}$ cell-dependent production of specific antibodies which, by a mimicry phenomenon, will deposit to joints of the mouse. ${ }^{19}$ This will cause an active inflammatory response, which would lead, eventually, to joint destruction. In fact, in experimental arthritis a large number of neutrophils accumulate into the joints of mice, which respond to collagen type II injection. Despite this model relies on strong immune components, which is assured by $\mathrm{B}$ cell expansion and $\mathrm{T}$ cell activation, the presence of typical cell types of innate immunity like the neutrophil is widely documented. ${ }^{1,2,20,21}$ To a certain extent, the active phase of the collagen-induce arthritis model mimics the flareup phase of human rheumatoid arthritis. The mechanisms, which would lead to such a marked infiltration of blood borne neutrophils into the joints are not fully investigated.

A recently developed model of arthritis, that is the seruminduced arthritis, ${ }^{22}$ has indicated a pivotal role for tissue resident cells such as the mast cell and the macrophage in bringing about the acute inflammatory arthritis which is characterised by marked recruitment of neutrophils. ${ }^{23}$ When mast cells are challenged by an external stimulus, often they respond by degranulation. In this process, mast cells also produce metabolites of arachidonic acid, including leukotrienes $\left(\mathrm{LTC}_{4}\right.$ and $\left.\mathrm{LTD}_{4}\right)$ and prostaglandins, particularly $\mathrm{PGD}_{2}{ }^{24}$ In addition, a number of powerful preformed inflammatory 'mediators' are released, including cytokines (IL-4, IL-5, IL-6, IL-13, TNF- $\alpha$ ) and chemokines (eg CXCL1 and CCL2), histamine, serglycin proteoglycans, and several mast cells-specific proteases (chymases, tryptases, and carboxypeptidase A; see references. ${ }^{25,26}$ Chymases and tryptases are the major proteins stored and secreted by mast cells ${ }^{27}$ and are potent chemotactic activities for neutrophils. ${ }^{28,29}$ Other mediators, such as histamine, can have both positive and negative immunomodulatory effects. Histamine can promote neutrophil recruitment by increasing CD62P expression on

Figure 2 Neutrophils migration after ClA within the synovial tissue of digits and knees joints. Synovial tissue of the digits (a-i) and knees (j-r) displayed an evident accumulation of transmigrated neutrophils (arrows) on days 21, 32 and 42 after collagen immunization. Data were analyzed using one way ANOVA followed by Dunnett's post hoc test. Results are expressed as the mean \pm s.e.m. taking a $P$-value less than 0.05 as significant ( $n=5$ animals per group). ${ }^{* *} P<0.01$ vs control group; $P<0.001$ vs digits. Picrosirius and H\&E-stain; scale bars: (a, c, e, g, j, l, n, p) $20 \mu \mathrm{m}$; (b, d, f, h, k, m, o, q) $5 \mu$ m. v, vessel; st, synovial tissue; $b$, bone. 


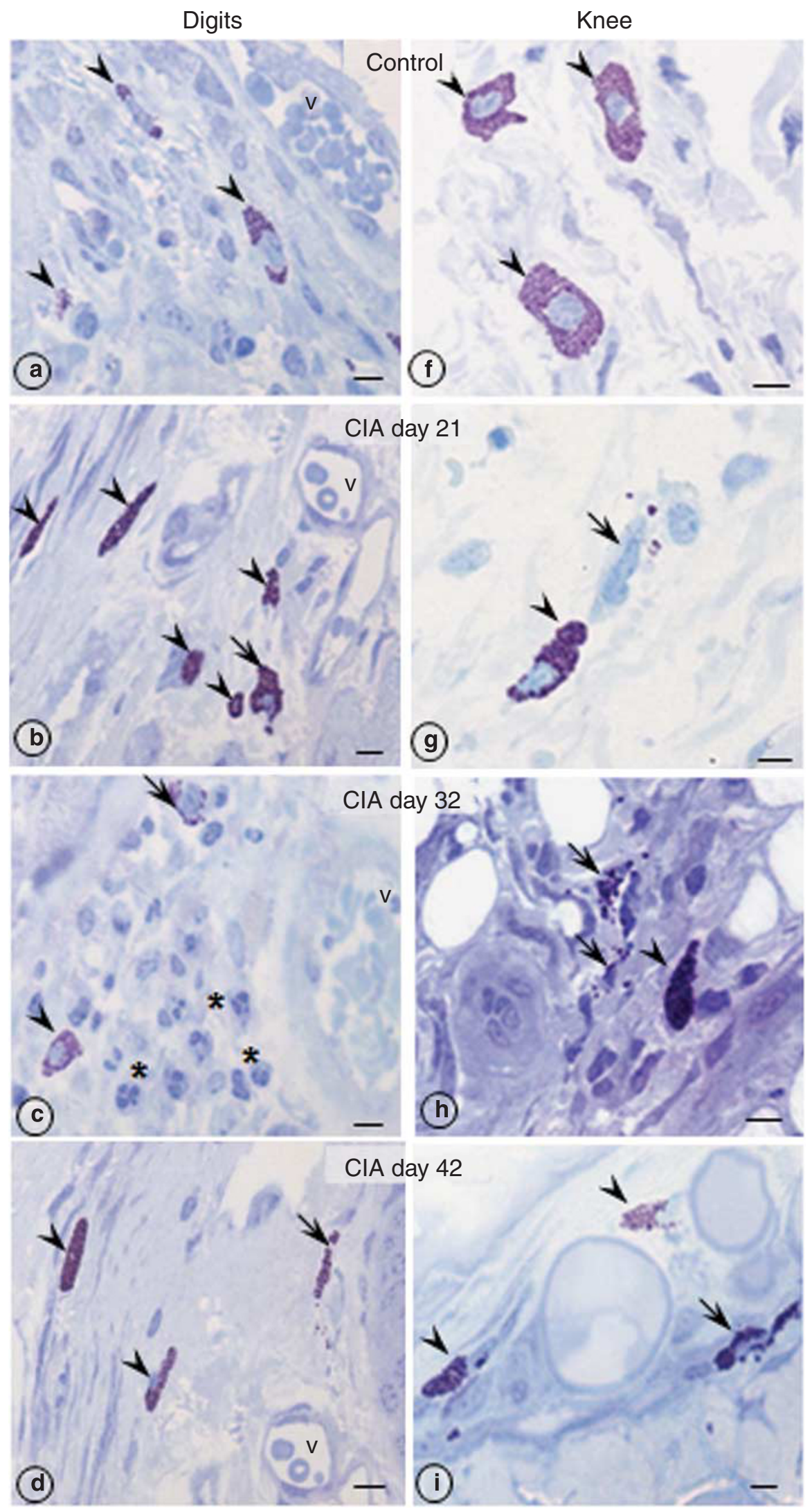

Figure 3 For the legend see next page. 

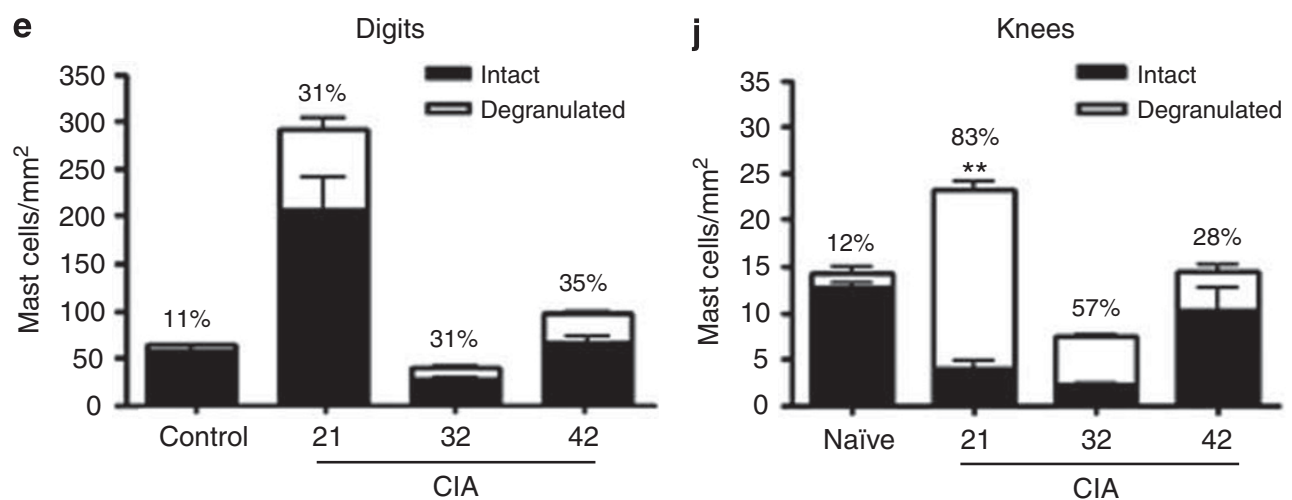

Figure 3 Mast cells in the digits and knees synovial tissue: histopathologic manifestations and quantification. Analysis of the digits (a-e) and knees (f-j) joints showed intact (arrowheads) and degranulated (arrows) mast cells in toluidine blue-stained sections. Representative sections demonstrating histopathology of a DBA/1J mice digits joints exhibiting a higher number of mast cells on day 21 in relation to the knees tissue; however, the level of degranulated cells was higher in the knees. On days 32 and 42 degranulated mast cells number was similar in the digits but gradually decreased in the knees. Data were analyzed using one way ANOVA followed by Dunnett's post hoc test Results are expressed as the mean \pm s.e.m. taking a $P$-value less than 0.05 as significant $\left(n=5\right.$ animals per group). ${ }^{* *} P<0.01$ vs control group. Scale bars: $5 \mu \mathrm{m}$. $v$, vessel.

Table 1 Treatment of CIA mice with prednisolone and nedocromil affects clinical scores and paw volumes

\begin{tabular}{llllll}
\hline \multirow{2}{*}{$\begin{array}{l}\text { Time-post } \\
\text { CIl (Day) }\end{array}$} & \multicolumn{2}{c}{ Clinical score } & & \multicolumn{2}{c}{ Paw volume } \\
\cline { 2 - 3 } \cline { 5 - 6 } & Prednisolone & Nedocromil & & Prednisolone & Nedocromil \\
\hline 27 & $75.8 \pm 18.5$ & $39.4 \pm 32.1$ & & $46.7 \pm 9.6$ & $20.0 \pm 9.9$ \\
32 & $84.7 \pm 9.7^{*}$ & $23.8 \pm 21.9$ & & $66.7 \pm 9.1^{* *}$ & $12.4 \pm 9.2$
\end{tabular}

Data reported are percentages (\%) of inhibition after treatment with Prednisolone $(4 \mu \mathrm{mol} / \mathrm{Kg})$ and Nedocromil $(2 \mathrm{mg} / \mathrm{Kg})$ from day 27 to day 32 . Data shown as Mean \pm s.e.m. of 5 mice per group. ${ }^{\star} P<0.05$; ${ }^{*} P<0.01$ vs control group day 32. Data were analyzed using one way ANOVA followed by Dunnett's post hoc test.

Table 2 Neutrophils and mast cells migration profile after prednisolone and nedocromil therapy in the digits

\begin{tabular}{lccc}
\hline & \multicolumn{3}{c}{ Digits synovial tissue } \\
\cline { 2 - 4 } Cell Type & Untreated & Prednisolone & Nedocromil \\
\hline Neutrophils & $1,512 \pm 21.2$ & $206 \pm 54.1^{* * *}$ & $289 \pm 39.4^{* * *}$ \\
Intact mast cells & $27.5 \pm 1.9$ & $203 \pm 20.0^{* *}$ & $6.7 \pm 1.0^{* * *}$ \\
Degranulated mast cells & $12.5 \pm 2.3$ & $137 \pm 10.4^{* * *}$ & $10.6 \pm 0.4$
\end{tabular}

Data report the number of the specified cell type per $\mathrm{mm}^{2}$ as quantified in digit synovial tissue of arthritic mice on day 32. Mice were either left untreated, or treated with Prednisolone $(4 \mu \mathrm{mol} / \mathrm{Kg})$ or Nedocromil $(2 \mathrm{mg} / \mathrm{Kg})$ from day 21 to day 32. Values are mean \pm s.e.m. of 5 mice pre group. ${ }^{* *} P<0.01$ and ${ }_{* * *} P<0.001$ vs untreated arthritic group.

the endothelium, an effect achieved by activation of its type 1 receptor $\left(\mathrm{H}_{1}\right) .^{30,31}$ Such an effect contribute to chemokine induced leukocyte recruitment, as seen both for neutrophils ${ }^{32,33}$ and eosinophils. ${ }^{34}$ Moreover, histamine inhibits neutrophil chemotaxis by acting on its type 2 receptor $\left(\mathrm{H}_{2}\right)$
Table 3 Neutrophils and mast cells migration profile after prednisolone and nedocromil therapy in the knees

\begin{tabular}{lrcc}
\hline & \multicolumn{3}{c}{ Knee synovial tissue } \\
\cline { 2 - 4 } Cell type & Untreated & Prednisolone & Nedocromil \\
\hline Neutrophils & $1,266 \pm 15$ & $1,174 \pm 41^{* * *}$ & $54 \pm 4.8^{* * *}$ \\
Intact mast cells & $2.2 \pm 0.2$ & $18.6 \pm 1.2^{* * *}$ & $0.7 \pm 0.1^{* *}$ \\
Degranulated mast cells & $5.4 \pm 0.1$ & $6.7 \pm 1.0$ & $1.3 \pm 0.1^{* * *}$
\end{tabular}

Data report the number of the specified cell type per $\mathrm{mm}^{2}$ as quantified in the knee synovial tissue of arthritic mice on day 32. Mice were either left untreated, or treated with Prednisolone $(4 \mu \mathrm{mol} / \mathrm{Kg})$ or Nedocromil $(2 \mathrm{mg} / \mathrm{Kg})$ from day 21 to day 32 . Values are mean \pm s.e.m. of 5 mice pre group. ${ }^{* * P}<0.01$ and ${ }^{* * *} P<0.001$ vs untreated arthritic group.

hence an effect mimicked by the $\mathrm{H}_{2}$ agonist impromidine, but not by the $\mathrm{H}_{1}$ agonist betahistine. $\mathrm{H}_{2}$ activation can also mediate histamine-induced reduction of neutrophil activation, superoxide formation and degranulation. ${ }^{35,36}$ Finally, histamine can have a positive effect on neutrophil recruitment not only by activating the $\mathrm{H}_{1}$ receptors, but also via the $\mathrm{H}_{4}$ receptor. $^{30,37}$ In more general terms, an appreciation of the role that mast cells would play not only in allergic and acute inflammation, but also in chronic settings, has recently emerged and being appreciated. ${ }^{38,39}$

Mast cells functions in arthritis are underscored by the findings that their activation and subsequent release of mediators are essential to the CIA development. ${ }^{40,41}$ Studies in mice lacking mast cells $\left(\mathrm{W} / \mathrm{W}^{\mathrm{v}}\right)$ have helped clarifying the role of this cell type in arthritis as well as inflammation: these mice failed to produce an inflammatory and erosive arthritis after infusion of autoantibodies. ${ }^{38}$ Consequently, in the absence of mast cells, there was no clinical or histologic evidence of arthritis into the joint. Although mast cells are implicated in the initiating events that lead to inflammatory 


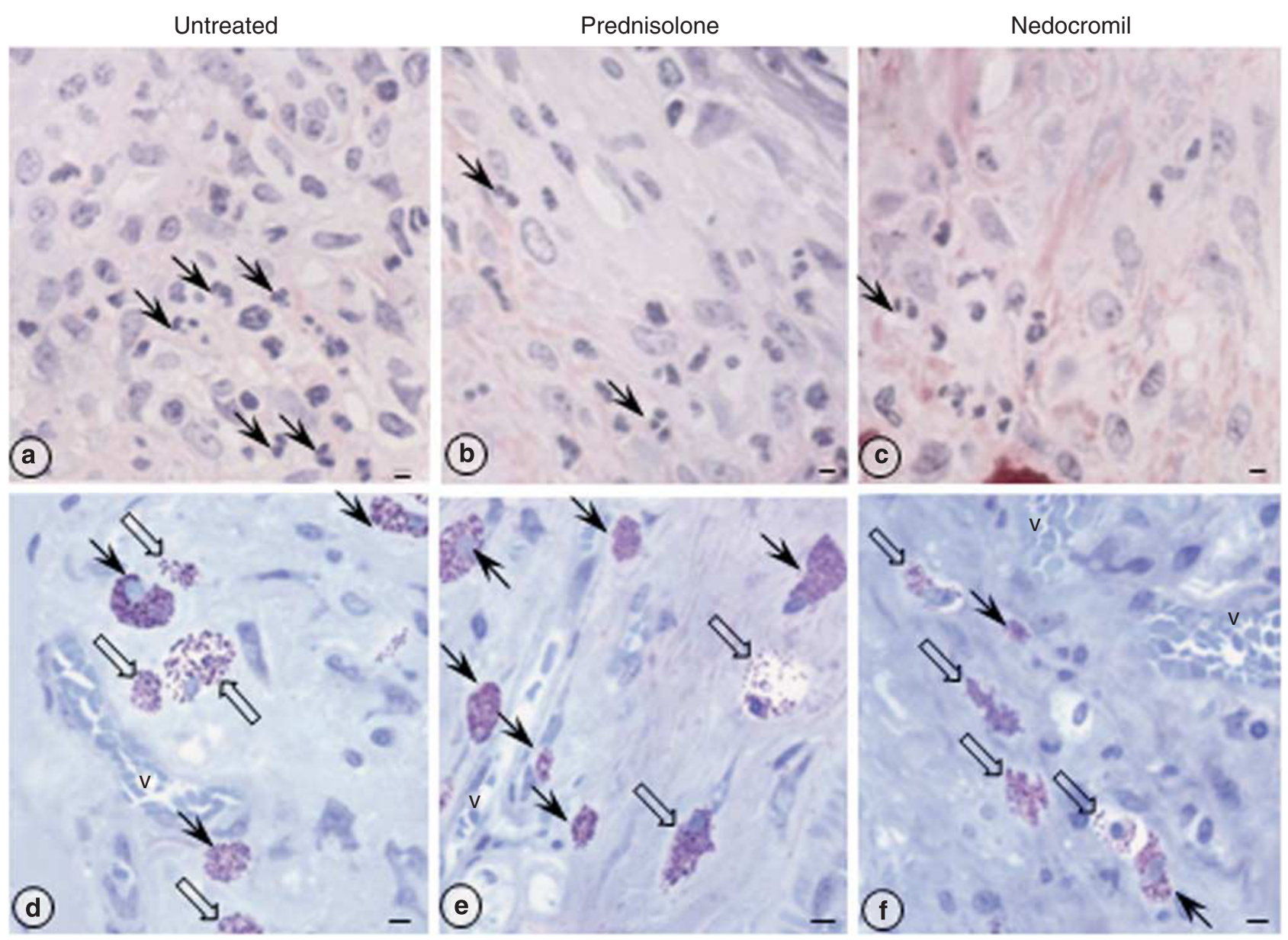

Figure 4 Synovial tissue of the digits after prednisolone and sodium nedocromil therapy. Histological analysis showing the influx of neutrophils (a-c) and mast cells (d-f) within the digits joints. Neutrophils (arrows) and intact (arrowheads) or degranulated (open arrows) mast cells were obtained from untreated and mice administered with prednisolone or sodium nedocromil, on day 32 after CIA. Picrosirius and H\&E-stain (a-c) and toluidine blue stains (d-f); scale bars: $10 \mu \mathrm{m}$.

arthritis, the exact mechanism by which they cause damage has not been defined. ${ }^{23}$

A novel outcome of the results presented here is a detailed analysis of the changes in mast cell morphology during the collagen-induced arthritis model over a wide time range. Moreover, intense influx of neutrophils could also be determined. Our detailed histological analyses of the digits and knees tissue samples revealed a different level of infiltration, suggesting that perhaps the disease starts in the latter before propagating to the former tissue site. Or even if there isn't any function or temporal association, our results indicate that neutrophil infiltration into the digits is much higher at time points when overt disease occurred (eg day 32); this was different from the profile of neutrophil tissue number in the knees samples which peaked at day 21, ie, at the beginning of the disease and then progressively decreased over time.

The importance of neutrophil trafficking has been determined in several inflammatory conditions; an association with CIA has recently been put forward, noting how neutropenia is associated with a reduced CIA response. In addition, depletion of neutrophils using specific antibodies, once CIA is clinically established, would arrest disease progression, demonstrating a critical requirement for these cells in perpetuating joint inflammation in these experimental conditions. $^{42}$

Having established, and in part confirmed, high presence of neutrophils within the affected joints, with a detailed and differential analysis between knees and digits, next we monitored the number and phenotype of mast cells. Again, differences between the two tissue sites emerged and this was also evident when the degree of mast cell degranulation was determined: in the knees, there is a high degree of mast cell degranulation at day 21 , that is, the disease onset, which then progressively decreases over time. In contrast, in the digits, there is a much higher number of mast cells at day 21 and the degree of degranulation remains, though with some fluctuations, constant over time. Collectively, these results indicate that at disease onset at peak of neutrophil influx and mast cell degranulation occurs in the knees and these precede the persistent inflammatory response that then occurs in the digits.

The next step of our study was to modulate macroscopic and histological outcomes testing the clinically active gluco- 
corticoid prednisolone ${ }^{43}$ and the mast cell stabiliser nedocromil. ${ }^{16,44}$ The glucocorticoid was used at a dose known to produce anti-arthritic actions. ${ }^{45}$ Indeed, in our settings, treatment of mice with prednisolone produces remarkable inhibitory effects both on the clinical score and on changes in volume. Nedocromil allowed us to test further the hypothesis of mast cell involvement. However, treatment of mice with this compound did not affect the clinical score in a significant manner, whereas it produced significant reduction in paw volume at its peak, eg. day 32. Analysis of the full time course of the experimental disease indicates how the clinical score begins (day 21), and in way precedes measurable increases in paw volume (evident from day 25). But can we relate any of these macroscopic pharmacological effects to changes in a tissue infiltration by neutrophils and/or to a degree of control of mast cell degranulation?

These analyses were conducted at day 32, since corresponded to high values for clinical score, paw volume and histological markers. Two well-known effects could be observed in the group of mice treated with prednisolone; these were a remarkable inhibition of neutrophil influx as well as much higher numbers of tissue mast cells. The process of neutrophil extravasation is extremely sensitive to the inhibitory effect of glucocorticoids including prednisolone. ${ }^{46,47}$

Glucocorticoids remain one of the most effective therapies for treatment of mast cell-related disorders. Glucocorticoids act in a time-dependent manner to potently suppress degranulation and cytokine production in mast cells in vitro. ${ }^{48-51}$ The fact that the prednisolone elicited the expected effects, ${ }^{52}$ though likely never investigated in such a detailed manner, in two different joints of the same arthritic mouse gave us confidence that the experimental system could be used to study the effect of nedocromil.

To this end, it is very interesting how the mast cell stabiliser produced uneven effects on the knees and digits synovial tissues. It can be noted that this compound did not provoke mastocytosis but rather it seemed to reduce total mast cell numbers at day 32; moreover it mildly affected the extent of mast cell degranulation, however it is plausible that it produced an overall inhibitory effect upon mast cell related responses, in view of the large decrease of total mast cells. There is scant knowledge that nedocromil can inhibit mast cell proliferation and differentiation. ${ }^{53}$ In a model of intestinal inflammatory process the colon of the rats treated with nedocromil sodium showed a significant decrease in the number of mast cells, concomitantly with reduction in inflammation and fibrosis. ${ }^{53}$ Initial stabilization of mast cells with nedocromil would reduce histamine release, reducing agonism at the histamine $\mathrm{H}_{4}$ receptor that modulates selective recruitment of mast cells, hence affecting the amplification of histamine-mediated immune responses. ${ }^{54}$ Of interest, nedocromil properties on the mast cell were associated with a highly significant reduction in the influx of neutrophils, which was particularly evident in the digit tissue samples. In addition, cromolyns display inhibitory activity in CIA,${ }^{55}$ but there are no studies revealing the effect of nedocromil during the development of arthritis. However, cromoglycates are not very potent suppressors of mast cells function, and their effect may not be entirely specific for this cell type. ${ }^{5}$

Considering that nedocromil produced an anti-inflammatory effect, which was more evident on paw volume, whereas it did not significantly affect the clinical score, we wish to propose that attenuation of the paw volume might likely be consequent to an inhibition of the inflammatory events within the digits. Along the same rational, we wish to propose that changes in the clinical score are consequent, or predictive, of inflammatory events within the knees. Mast cell stabilisers, including cromolyn and more recently developed synthetic compounds, are used in clinical settings to control allergic responses ${ }^{56}$ which are highly reliant on mast cell degranulation and activation. These compounds also possess anti-inflammatory activities in acute settings, ${ }^{57}$ whereas their potential ability to influence a chronic inflammatory process has been rarely investigated.

Here we showed that bovine type II collagen induced an inflammatory process characterized by mast cell degranulation, suggesting a potential driving force in propagating inflammatory circuits leading to recruitment of blood-borne neutrophils. However, the different degree of joint involvement suggests a time-related implication for digits and knees during CIA development. These results provide evidence for local alterations where mast cells contribute to the initiation of inflammatory arthritis and may be targeted in intervention strategies.

\section{ACKNOWLEDGEMENTS}

Financial Support: Fundação de Amparo à Pesquisa do Estado de São Paulo - FAPESP (Grants 2005/51875-0 and 2007/55348-0 to TAP); Conselho

Nacional de Desenvolvimento Científico e Tecnológico-CNPq (Grant 306074/2007-9 to SMO), the Wellcome Trust UK (Grant 083551/Z/07/Z).

\section{DISCLOSURE/CONFLICT OF INTEREST}

The authors declare no conflict of interest.

1. Williams A, Richards $\mathrm{P}$, Thomas $\mathrm{E}$, et al. Interferon-gamma protects against the development of structural damage in experimental arthritis by regulating polymorphonuclear neutrophil influx into diseased joints. Arthritis Rheum 2007;56:2244-2254.

2. Grespan R, Fukada S, Lemos $\mathrm{H}$, et al. CXCR2-specific chemokines mediate leukotriene B4-dependent recruitment of neutrophils to inflamed joints in mice with antigen-induced arthritis. Arthritis Rheum 2008;58:2030-2040.

3. Tetlow L, Woolley D. Mast cells, cytokines, and metalloproteinases at the rheumatoid lesion: dual immunolocalisation studies. Ann Rheum Dis 1995;54:896-903.

4. Firestein G. Evolving concepts of rheumatoid arthritis. Nature 2003;423:356-361.

5. Eklund K. Mast cells in the pathogenesis of rheumatic diseases and as potential targets for anti-rheumatic therapy. Immunol Rev 2007;217: 38-52.

6. Metcalfe D. Mast cells and mastocytosis. Blood 2008;112:946-956.

7. Kalesnikoff J, Galli S. New developments in mast cell biology. Nat Immunol 2008;9:1215-1223.

8. Galli S, Kalesnikoff J, Grimbaldeston M, et al. Mast cells as 'tunable' effector and immunoregulatory cells: recent advances. Annu Rev Immunol 2005;23:749-786. 
9. Rivera J, Gilfillan A. Molecular regulation of mast cell activation. J Allergy Clin Immunol 2006;117:1214-1225, quiz 1226.

10. Galli S, Grimbaldeston M, Tsai M. Immunomodulatory mast cells: negative, as well as positive, regulators of immunity. Nat Rev Immunol 2008;8:478-486.

11. Sylvestre $D$, Ravetch J. A dominant role for mast cell Fc receptors in the Arthus reaction. Immunity 1996;5:387-390.

12. Magnusson S, Pejler G, Kleinau S, et al. Mast cell chymase contributes to the antibody response and the severity of autoimmune arthritis. FASEB J 2009;23:875-882.

13. Malone D, Irani A, Schwartz $L$, et al. Mast cell numbers and histamine levels in synovial fluids from patients with diverse arthritides. Arthritis Rheum 1986;29:956-963.

14. Woolley D. The mast cell in inflammatory arthritis. N Engl J Med 2003;348:1709-1711.

15. Shin K, Nigrovic P, Crish J, et al. Mast cells contribute to autoimmune inflammatory arthritis via their tryptase/heparin complexes. J Immunol 2009;182:647-656.

16. Riley $\mathrm{P}$, Mather $M$, Keogh $R$, et al. Activity of nedocromil sodium in mast-cell-dependent reactions in the rat. Int Arch Allergy Appl Immunol 1987;82:108-110.

17. Ahluwalia $\mathrm{P}$, Anderson $\mathrm{D}$, Wilson $\mathrm{S}$, et al. Nedocromil sodium and levocabastine reduce the symptoms of conjunctival allergen challenge by different mechanisms. J Allergy Clin Immunol 2001;108:449-454.

18. Arnett $\mathrm{H}$, Viney J. Considerations for the sensible use of rodent models of inflammatory disease in predicting efficacy of new biological therapeutics in the clinic. Adv Drug Deliv Rev 2007:59:1084-1092.

19. Amirahmadi $S$, Pho $M$, Gray $R$, et al. An arthritogenic monoclonal antibody to type II collagen, CII-C1, impairs cartilage formation by cultured chondrocytes. Immunol Cell Biol 2004;82:427-434.

20. Yang $Y$, Hutchinson $P$, Leech $M$, et al. Exacerbation of adjuvant arthritis by adrenalectomy is associated with reduced leukocyte lipocortin 1. J Rheumatol 1997;24:1758-1764.

21. Tanaka D, Kagari $T$, Doi $H$, et al. Essential role of neutrophils in antitype II collagen antibody and lipopolysaccharide-induced arthritis. Immunology 2006;119:195-202.

22. Kouskoff V, Korganow A, Duchatelle V, et al. Organ-specific disease provoked by systemic autoimmunity. Cell 1996;87:811-822.

23. Wipke B, Allen P. Essential role of neutrophils in the initiation and progression of a murine model of rheumatoid arthritis. J Immunol 2001;167:1601-1608.

24. Raud J. Intravital microscopic studies on acute mast cell-dependent inflammation. Acta Physiol Scand Suppl 1989;578:1-58.

25. Schramm R, Thorlacius $H$. Neutrophil recruitment in mast celldependent inflammation: inhibitory mechanisms of glucocorticoids. Inflamm Res 2004:53:644-652.

26. Pejler $G$, Abrink $M$, Ringvall $M$, et al. Mast cell proteases. Adv Immunol 2007:95:167-255.

27. Caughey G. Mast cell tryptases and chymases in inflammation and host defense. Immunol Rev 2007;217:141-154.

28. Tani K, Ogushi F, Kido H, et al. Chymase is a potent chemoattractant for human monocytes and neutrophils. J Leukoc Biol 2000;67:585-589.

29. Huang C, De Sanctis G, O'Brien P, et al. Evaluation of the substrate specificity of human mast cell tryptase beta I and demonstration of its importance in bacterial infections of the lung. J Biol Chem 2001;276:26276-26284

30. Gaboury J, Johnston B, Niu X, et al. Mechanisms underlying acute mast cell-induced leukocyte rolling and adhesion in vivo. J Immunol 1995;154:804-813.

31. Kubes $P$, Granger D. Leukocyte-endothelial cell interactions evoked by mast cells. Cardiovasc Res 1996;32:699-708.

32. Tailor A, Tomlinson A, Salas A, et al. Dexamethasone inhibition of leucocyte adhesion to rat mesenteric postcapillary venules: role of intercellular adhesion molecule 1 and KC. Gut 1999;45:705-712.

33. Perretti $M$, Harris J, Flower R. A role for endogenous histamine in interleukin-8-induced neutrophil infiltration into mouse air-pouch: investigation of the modulatory action of systemic and local dexamethasone. Br J Pharmacol 1994;112:801-808.

34. Ajuebor $M$, Das $A$, Virág $L$, et al. Role of resident peritoneal macrophages and mast cells in chemokine production and neutrophil migration in acute inflammation: evidence for an inhibitory loop involving endogenous IL-10. J Immunol 1999;162:1685-1691.
35. Triggiani M, Petraroli A, Loffredo S, et al. Differentiation of monocytes into macrophages induces the upregulation of histamine $\mathrm{H} 1$ receptor. J Allergy Clin Immunol 2007;119:472-481.

36. Jutel $M$, Akdis $M, A k d i s ~ C$. Histamine, histamine receptors and their role in immune pathology. Clin Exp Allergy 2009;39:1786-1800.

37. Takeshita K, Sakai K, Bacon K, et al. Critical role of histamine $\mathrm{H} 4$ receptor in leukotriene B4 production and mast cell-dependent neutrophil recruitment induced by zymosan in vivo. J Pharmacol Exp Ther 2003;307:1072-1078.

38. Lee $D$, Friend $D$, Gurish $M$, et al. Mast cells: a cellular link between autoantibodies and inflammatory arthritis. Science 2002; 297:1689-1692.

39. Metz $M$, Grimbaldeston $M$, Nakae $S$, et al. Mast cells in the promotion and limitation of chronic inflammation. Immunol Rev 2007:217: 304-328.

40. Paniagua $R$, Sharpe $O$, Ho $P$, et al. Selective tyrosine kinase inhibition by imatinib mesylate for the treatment of autoimmune arthritis. J Clin Invest 2006;116:2633-2642.

41. Magnusson $\mathrm{S}$, Andrén $\mathrm{M}$, Nilsson $\mathrm{K}$, et al. Amelioration of collageninduced arthritis by human recombinant soluble FcgammaRllb. Clin Immunol 2008;127:225-233.

42. Eyles J, Hickey $M$, Norman $M$, et al. A key role for G-CSF-induced neutrophil production and trafficking during inflammatory arthritis. Blood 2008;112:5193-5201.

43. Rhen T, Cidlowski J. Antiinflammatory action of glucocorticoids-new mechanisms for old drugs. N Engl J Med 2005;353:1711-1723.

44. RM A, ST H. Nedocromil sodium: a review of its anti-inflammatory properties and clinical activity in the treatment of asthma. In: Kay A (edn). Allergy and Asthma. New Trends and Approaches to Therapy. Oxford: Blackwell Scientific Publications, 1989, pp 171-188.

45. van Everdingen A, Jacobs J, Siewertsz Van Reesema D, et al. Low-dose prednisone therapy for patients with early active rheumatoid arthritis: clinical efficacy, disease-modifying properties, and side effects: a randomized, double-blind, placebo-controlled clinical trial. Ann Intern Med 2002;136:1-12.

46. Ciulla $T$, Walker J, Fong $D$, et al. Corticosteroids in posterior segment disease: an update on new delivery systems and new indications. Curr Opin Ophthalmol 2004;15:211-220.

47. Krivic $A$, Majerovic $M$, Jelic $l$, et al. Modulation of early functional recovery of Achilles tendon to bone unit after transection by BPC 157 and methylprednisolone. Inflamm Res 2008;57:205-210.

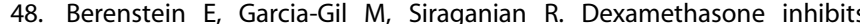
receptor-activated phosphoinositide breakdown in rat basophilic leukemia (RBL-2H3) cells. J Immunol 1987;138:1914-1918.

49. Andrade M, Hiragun T, Beaven M. Dexamethasone suppresses antigeninduced activation of phosphatidylinositol 3-kinase and downstream responses in mast cells. J Immunol 2004;172:7254-7262.

50. Nakamura R, Okunuki $\mathrm{H}$, Ishida $\mathrm{S}$, et al. Gene expression profiling of dexamethasone-treated RBL-2H3 cells: induction of anti-inflammatory molecules. Immunol Lett 2005;98:272-279.

51. Park S, Beaven M. Mechanism of upregulation of the inhibitory regulator, src-like adaptor protein (SLAP), by glucocorticoids in mast cells. Mol Immunol 2009;46:492-497.

52. Mihara K, Almansa C, Smeets $R$, et al. A potent and selective p38 inhibitor protects against bone damage in murine collagen-induced arthritis: a comparison with neutralization of mouse TNFalpha. $\mathrm{Br} J$ Pharmacol 2008;154:153-164.

53. Xu X, Weksler-Zangen S, Pikarsky A, et al. Mast cells involvement in the inflammation and fibrosis development of the TNBS-induced rat model of colitis. Scand J Gastroenterol 2002;37:330-337.

54. Zampeli $\mathrm{E}$, Tiligada $\mathrm{E}$. The role of histamine $\mathrm{H} 4$ receptor in immune and inflammatory disorders. Br J Pharmacol 2009;157:24-33.

55. Kobayashi $\mathrm{Y}$, Okunishi $\mathrm{H}$. Mast cells as a target of rheumatoid arthritis treatment. Jpn J Pharmacol 2002;90:7-11.

56. Cheng J, Arnold R. Pharmacoeconomic review of medical management of persistent asthma. Allergy Asthma Proc; 29: 109-122.

57. Jin $Y$, Silverman A, Vannucci S. Mast cells are early responders after hypoxia-ischemia in immature rat brain. Stroke 2009;40:3107-3112.

58. Iwai $\mathrm{H}$, Kozono $\mathrm{Y}$, Hirose $\mathrm{S}$, et al. Amelioration of collagen-induced arthritis by blockade of inducible costimulator-B7 homologous protein costimulation. J Immunol 2002;169:4332-4339. 